Sheridan, L. P., Scott, A. J., \& Campbell, A. M. (2016). Perceptions and Experiences of Intrusive Behavior and Stalking Comparing LGBTIQ and Heterosexual Groups. Journal of Interpersonal Violence, 0886260516651313.

\begin{abstract}
Taking a mixed methods approach, perceptions and experiences of intrusive behavior within individuals identifying as lesbian, gay, bisexual, transgender, intersex or queer (LGBTIQ) were compared with a matched (in terms of age, sex and income bracket) sample of individuals identifying as heterosexual $(N=214)$. Despite only minor differences between the LGBTIQ and heterosexual groups concerning perceptions of the acceptability of a range of 47 intrusive behaviors, the LGBTIQ group reported higher levels of experiencing these behaviors and higher rates of stalking victimization (self-reported rates of $35.5 \%$, vs. $15.0 \%$ ). Participant sex and personal experience of being stalked were minimally associated with perceptions of the acceptability of the 47 intrusive behaviors. Sexual orientation significantly predicted whether a person had experienced stalking victimization, participant sex did not. The qualitative analysis revealed that some experiences of intrusive behavior were shared by the two groups, while others represented a unique subset of intrusions that related to sexual orientation.
\end{abstract}




\section{Perceptions and Experiences of Intrusive Behavior and Stalking: Comparing LGBTIQ and Heterosexual Groups}

\section{Introduction}

Unlike most criminal activities, stalking comprises a series of often-legal behaviors. As such, it can be difficult to define and targets are often unaware of their victim status (Garcia, 2010). In a typical stalking case, behaviors that are not anxiety provoking separately (e.g., phone calls, the giving of gifts and e-mailing) can be considered threatening when examined within the context of a multitude of activities that collectively equate to stalking (Sinclair \& Frieze, 2002). Summaries of legal definitions of stalking in Western populations conclude that it is a series of intentional and repeated behaviors directed by one person towards another that are unwanted and would be viewed by a reasonable person as fear provoking and/or threatening (Spitzberg \& Cupach, 2007).

Prior studies of stalking victimization have examined stalking as it relates to various factors that include sex (e.g., Sheridan, North, \& Scott, 2014), age (e.g., Sheridan, Scott, \& North, 2014), culture (e.g., Chapman \& Spitzberg, 2003), prior relationship status (e.g., Sheridan \& Lyndon, 2012), and lifestyle factors (e.g., Reyns, Henson, Fisher, Fox, \& Nobles, 2015). However, a potentially at risk group has so far been excluded from this research, namely individuals identifying as lesbian, gay, bisexual, transgender, intersex or queer (LGBTIQ). The present research will compare two matched samples of LGBTIQ and heterosexual individuals on their perceptions and experiences of intrusive behavior. It should be noted that some of the intrusive behaviors examined in this work and covered in the literature review will not necessarily equate to stalking when considered in isolation, but may often be 
constituent of a course of conduct that represents stalking. A qualitative measure of stalking will also be included in the present research, allowing for a comparison of the nature of actual stalking experiences between the two groups.

\section{Literature Review}

Perceptions. Several factors have been demonstrated to influence how stalking is perceived, including sex, prior relationship status and personal experience. Most of the relevant works report that women are more likely than men to perceive intrusive situations as stalking and/or as serious (Dennison \& Thomson, 2002, employing vignettes and an Australian community sample; Finnegan \& Timmons Fritz, 2012, employing vignettes and a US student sample; Hills \& Taplin, 1998, employing vignettes and an Australian community sample; Lambert, Smith, Geistman, Cluse-Tolar, \& Jiang, 2013, employing a survey and a US student sample; McKeon, McEwan \& Luebbers, 2015, employing a measure of stalking myths and Australian police and community samples; Scott, Rajakaruna, Sheridan, \& Gavin, 2015, employing vignettes and Australian, UK and US community samples; Sinclair, 2012, employing vignettes and a US student sample; and Yanowitz, 2006, employing a list of behaviors and a US student sample). A smaller number of works have recorded no, or minimal, sex differences in perceptions of what constitutes stalking (Cass, 2011; Cass \& Rosay, 2012, employing vignettes and US student samples; Kinkade, Burns, \& Fuentes, 2005, employing vignettes and a US student sample). How can this reasonably consistent pattern of findings be explained? A potential interpretation is provided by the defensive attribution bias (see e.g., Elkins, Philips, \& Konopaske, 2002), which is the tendency for people to identify with targets they judge to be similar to themselves. A recent study that made participant, perpetrator, and target sex 
comparisons in relation to a stalking scenario concluded that men identify more closely with the role of the perpetrator, whereas women identify more closely with the role of the victim, irrespective of the sex of the perpetrator and victim (Scott et al., 2015).

The research cited above compared perceptions on a range of variables, including the extent to which behavior constituted stalking and necessitated police intervention. Seven studies by Sheridan and colleagues (Björklund, HäkkänenNyholm, Roberts \& Sheridan, 2010; Chiri, Sica, Roberts, \& Sheridan, 2009; Jagessar \& Sheridan, 2004; Pereira, Matos, Sheridan, \& Scott, 2015; Sheridan, Davies \& Boon 2001, Sheridan, Gillett, \& Davies, 2000, 2002) have found that non-representative student and community samples of British men, Portuguese men, British women, Italian women, Finnish women and Trinidadian women hold similar perceptions regarding which of a list of intrusive behaviors are unacceptable. This finding supports the defensive attribution bias explanation of sex differences in judgments concerning stalking cases, in that when participants are asked to provide context-free judgments without details of a hypothetical perpetrator and target, sex differences are not identified. The methodology developed by Sheridan and colleagues will be used in the present research. A list of intrusive behaviors will be presented to participants and they will be asked to indicate whether they perceive each of the behaviors to be acceptable or unacceptable. The list will then be presented to participants a second time and they will be asked to indicate whether or not they have experienced each of the behaviors. Research suggests that personal experience of being stalked influences perceptions of stalking (Fairchild, 2010; Yanowitz, 2006). For example, Yanowitz's study revealed that men who had either personally experienced, or who were familiar with someone with experience of stalking victimization, were more likely to perceive 
intrusive behaviors as constituent of stalking than men without personal experience or familiarity.

Experiences. Several factors are thought to increase the likelihood of experiencing stalking victimization such as sex, age and socioeconomic status. For example, incidence rates of stalking among the university student population appear to be considerably higher than those within the general population (e.g., Fisher, Cullen, \& Turner, 2002; Jordan, Wilcox, \& Pritchard, 2007; Philips \& Morissey, 2004; Ravensburg \& Miller, 2003). Members of minority communities are generally noted to experience higher rates of discrimination and harassment than are nonmembers (see Simpson \& Eriksson, 2011). Simpson and Eriksson proposed that the size of communities influences the rate of discrimination and harassment received. Minority communities tend to be smaller in terms of their population and size (numerical minority) in comparison to the wider population, and it may extrapolated therefore that minority communities lack the ability to deflect stalking behaviors due to the deficiency of power implied by numerical minority.

Katz-Wise and Hyde (2012) examined 386 studies relating to prevalence and types of victimization among individuals identifying as lesbian, gay or bisexual (LGB). LGB individuals were reported to have experienced high rates of harassment, the highest rates being for verbal harassment (55\%), sexual harassment (45\%), relational victimization (44\%) and discrimination (44\%). In the 65 studies that compared LGB and heterosexual groups, LGB individuals were significantly more likely to be bullied, discriminated against, physically and sexually assaulted, verbally and emotionally abused, and threatened than heterosexual individuals. The studies covered a variety of settings, including school, the family, the workplace, public spaces, and healthcare settings. Overall sex differences were small, but women, 
regardless of sexual orientation, were more likely to experience sexual harassment than men.

In addition to the aforementioned external stressors, individuals identifying with a minority sexual orientation may experience internal stressors, including internalized homophobia, concealment of individual sexual orientation and fear of rejection (Derlega et al., 2011). Due to these stressors, particularly fear of rejection and membership of the minority social group, it has been suggested that individuals engaged in intimate relationships may be more likely to exhibit aggressor behaviors, or become victim to them, when the relationship breaks down (Carvalho, Lewis, Derlega, Winstead, \& Viggiano, 2011; Derlega et al., 2011). Derlega et al. examined unwanted pursuit following relationship breakdown in a sample of 165 individuals identifying as lesbian, gay, bisexual or transgender (LGBT). Only 12 individuals indicated they had not been the target or perpetrator of post-relational pursuit. Furthermore, Dank, Lachman, Zweig, and Yahner (2014) found that in a sample of 5,647 youth, LGB individuals reported higher levels of victimization and perpetration for all types of dating violence examined compared to heterosexual individuals. One suggestion to arise from Derlega et al.'s (2011) research was that controlling behaviors are more consistent with male as opposed to female views of relationships. In support of most stalking-related research with heterosexual participants, they found that men were more likely than women to engage in unwanted pursuit behaviors (see also Katz-Wise \& Hyde, 2012). It is important to note that 'unwanted pursuit' tends to refer to a situation where one person seeks to obtain or restart a romantic relationship with the target of their pursuit, and this may develop into stalking (see Cupach \& Spitzberg, 2004). In the Derlega et al. work, behaviors at the lower end of a continuum from seemingly innocuous intrusions to dangerous and threatening 
behaviors were classified as 'unwanted pursuit'. They reserved the label 'stalking' for persistent and threatening or dangerous acts that would meet legal definitions of stalking.

Although males appear to engage in stalking more often than females, women do stalk and men are victimized. It has been suggested that between $10 \%$ and $25 \%$ of stalking cases involve female stalkers, many sharing similar motives and behaviors with their male counterparts (see e.g., Baum, Catalano, Rand, \& Rose, 2009). Research also suggests that the effects of victimization are similar in same- and opposite-sex cases (e.g., McEwan, Mullen, \& Purcell, 2007, Sheridan, North, \& Scott, 2014), although men are less likely than women to report feeling fearful or report their victimization to the police (e.g., Englebrecht \& Reyns, 2011). Rates of malemale stalking range from $50 \%$ to $62 \%$ of subsamples where all victims were men, and female-female stalking rates range from $9 \%$ to $25 \%$ of subsamples where all victims were women (Australian Bureau of Statistics, 2010; Baum et al., 2009). What remains unknown from these studies is the proportion of individuals identifying as LGBTIQ among both perpetrators and victims. After examining 52 Swedish and 42 Australian stalking cases of same-sex stalking and comparing them with larger numbers of opposite-sex cases, Strand and McEwan (2011) concluded that opposite-sex stalker motivations often stemmed from a prior-intimate relationship, while same-sex stalker motivations often stemmed from a grievance against the victim. The stalkers in this work came from a non-random, selective pool of criminal and mental health-based samples. Further, it is unknown how much of the stalking was engaged in by or directed towards LGBTIQ individuals. 


\section{Aim and Hypotheses}

Perceptions of stalking have been examined in the wider population and have been found to be broadly similar within and between sample groups. No works have directly investigated perceptions of stalking among LGBTIQ individuals. Neither have experiences of individual intrusive behaviors and rates of stalking been examined within this population. The aim of the present research is to examine perceptions and experiences of intrusive behavior with matched samples of LGBTIQ and heterosexual individuals. We formed the following five hypotheses: (1) LGBTIQ individuals will perceive intrusive behavior similarly to heterosexual individuals; (2) LGBTIQ individuals will report having experienced more intrusive behaviors than heterosexual individuals; (3) LGBTIQ individuals will report higher rates of stalking victimization than heterosexual individuals; (4) women and men will perceive intrusive behaviors to be unacceptable at similar rates; (5) individuals with experience of stalking victimization will perceive more intrusive behaviors to be unacceptable than individuals without experience of stalking victimization. We also examine which best predicts whether a participant has been stalked, their sex or their sexual orientation.

\section{Method}

\section{Research Design}

The present research used a non-experimental design to examine perceptions and experiences of intrusive behavior among individuals identifying as LGBTIQ and heterosexual. Analyses initially explored whether LGBTIQ and heterosexual individuals differ with regard to their perceptions and experiences of 47 intrusive behaviors. Analyses then explored whether LGBTIQ and heterosexual individuals 
differ with regard to their rates of stalking victimization. Finally, analyses explored whether men and women differ in their perceptions of 47 intrusive behaviors and whether there is a relationship between experiences and perceptions of the 47 intrusive behaviors. The study uses a concurrent, fixed mixed-methods approach as qualitative data are used to describe participants' worst experiences of the 47 intrusive behaviors. The qualitative and quantitative results were analyzed separately and then related during interpretation.

\section{Participants}

A convenience sample of individuals identifying as LGBTIQ and heterosexual was recruited. Issues affecting LGB people are often the same for individuals identifying as transgender and intersex, especially regarding harassment and discrimination (Comfort \& McCausland, 2013), and as such no individuals identifying with any particular sexual orientation were excluded. The study was promoted online through the social media networks Facebook and TUMBLR. Four radio interviews with specialist LGBTIQ themed stations in Perth, Sydney and Melbourne were conducted to help promote the survey. LGBTIQ advocacy and community groups (such as GLBTI Rights in Ageing Inc., The WA AIDS Council, Living Proud, The Queer Department of the Curtin University [Perth] Student Guild, and Freedom Centre) were asked to promote the study via posters that contained an URL and a QR code that linked Internet users to the survey.

The initial sample comprised 354 Australian residents, 70 of which were excluded from the study because: more than five per cent of their data was missing, long strings of consecutive 'yes' or 'no' responses were observed, responses to the qualitative section of the questionnaire were bizarre or non-genuine. A sample of 284 
Australian residents remained: 107 LGBTIQ individuals and 177 heterosexual individuals. A subsample of heterosexual individuals was matched to the LGBTIQ individuals according to sex, age and income bracket. The final sample comprised 107 LGBTIQ individuals and 107 heterosexual individuals $(\mathrm{N}=214)$. The sample, broken down by sex, age and income, is displayed in Table 1.

---Table 1 about here---

\section{Materials}

Participants completed an online version of the 'Stalking: Perceptions and Prevalence Questionnaire', originally developed by Sheridan et al. (2001). An original version of the questionnaire containing 42 intrusive behaviors has been employed in four previous studies (Jagessar \& Sheridan, 2004; Sheridan et al., 2001; Sheridan et al., 2000, 2002); and a modified version containing 47 intrusive behaviors has been used in three previous studies (Björklund et al., 2010; Chiri et al., 2009; Pereira et al., 2015). The samples that have completed the questionnaire in these previous works comprise: a Trinidadian community sample of 354 women, a UK community sample of 348 women, a UK community sample of 80 women, a UK community sample of 210 men, a Finnish sample student sample of 615 women, a Portuguese student sample of 91 men, and an Italian student sample of 195 women. All these samples, like the current sample, were non-representative of their broader populations.

The questionnaire comprised four sections. Section 1 asked participants to provide demographic details concerning age, sex, income bracket and sexual orientation. Section 2 contained a list of 47 intrusive behaviors, and asked participants to indicate whether they perceived each of the behaviors to be unacceptable or 
acceptable. The behaviors are designed to represent a continuum from mildly intrusive acts (e.g., agreeing with your every word) to serious intrusive acts that would be considered criminal offences (e.g., forced sexual contact). Section 3 contained the same list of 47 intrusive behaviors, and asked participants to indicate whether or not they have experienced each of the behaviors. Section 4 asked participants who have experienced one or more of the 47 intrusive behaviors to write about their worst experience, with particular reference to the behavior of the person. A total of 116 participants completed Section 4 (67 LGBTIQ, 49 heterosexual) of the questionnaire, responding to the question: If you have experienced any of the 47 behaviors, could you please tell us some more about what you would consider to be the most serious incident? Rates of stalking were determined by two published experts on stalking, one of whom was independent of the study, who categorized participants as having been 'stalked' or 'not stalked'.

\section{Procedure}

The poster and online advertisement that promoted the research asked for 15 minutes of the reader's time to "complete a survey on harassment", whether they had ever experienced this type of activity or not. The website that participants were directed to provided an information page that stated the purpose of the research (to better understand both attitudes towards and experiences of intrusive behavior in individuals identifying as LGBTIQ and heterosexual) and their rights when participating. Contained in the information page were instructions to find a quiet and private area to complete the questionnaire. Upon completion of the questionnaire, participants were debriefed regarding the use of the data and provided with details of local, national and international counselling services and help services for stalking 
victims. Participants could exit the questionnaire at any time without fear of penalty or judgment.

\section{Results}

\section{H1: Sexual Orientation and Perceptions of Intrusive Behavior}

Chi-square analyses compared LGBTIQ and heterosexual group perceptions of the 47 intrusive behaviors and five were significant. Table 2 shows that LGBTIQ individuals were more likely to perceive four behaviors to be unacceptable than heterosexual individuals. None of the behaviors were serious. One behavior was less likely to be perceived as unacceptable by the LGBTIQ group.

\section{H2: Sexual Orientation and Experiences of Intrusive Behavior}

Chi-square analyses compared LGBTIQ and heterosexual group experiences of the 47 intrusive behaviors and 22 were significant. Table 3 shows that LGBTIQ individuals were more likely to have experienced all 22 behaviors than heterosexual individuals. These behaviors were at the more serious end of the scale. When the 47 behaviors were rank ordered according to the proportion of the total sample that perceived them to be unacceptable, perceptions of unacceptability ranged from $6.1 \%$ to $100.0 \%(M=78.01, S D=28.18)$. For the 22 behaviors that were more likely to be experienced by LGBTIQ individuals, perceptions of unacceptability ranged from $45.3 \%$ to $100.0 \%(M=89.99, S D=15.87)$.

\section{H3: Sexual Orientation and Rates of Stalking Victimization}

Chi-square analysis compared LGBTIQ and heterosexual group rates of stalking victimization and was significant, $\chi^{2}(1)=11.99, p=.001$. LGBTIQ 
individuals were more likely to report experiencing stalking victimization than heterosexual individuals ( $35.5 \%$ vs. $15.0 \%$ ). A binary logistic regression examined which of the variables, participant sex or sexual orientation, best predicted whether a participant had experienced stalking victimization. The significant predictive model explained between 4.9\% (Cox and Snell R square) and 7.3\% (Nagelkerke R square) of variance in rates of stalking victimization, $\chi^{2}(2, \mathrm{~N}=208)=10.39, p=.006$. Sexual orientation was the only significant predictor of whether or not a participant had experienced stalking victimization, $b=1.06$, Wald $\chi^{2}(1)=9.48, p=.002$.

\section{H4: Participant Sex and Perceptions of Intrusive Behavior}

Chi-square analyses compared male and female group perceptions of the 47 intrusive behaviors and three were significant. Women were more likely to perceive all three behaviors to be unacceptable than men: "Someone at a social event such as a

party asks you if you would like to have sex with him/her" $(68.0 \%$ vs. $48.8 \%), \chi^{2}(1)=$ 7.61, $p=.006$; "Finding out information about you (phone numbers, marital status, address, hobbies) without asking you directly" $(78.1 \%$ vs. $63.8 \%), \chi^{2}(1)=5.11, p=$ .024 ; "Seeing him/her at the same time each day" (50.8\% vs. $36.3 \%), \chi^{2}(1)=4.20, p$ $=.040$. Data from the $5.6 \%$ of LGBTIQ individuals who did not identify with a binary sex category were excluded from this analysis as associated cell sizes were too small.

\section{H5: Experience of Stalking Victimization and Perceptions of Intrusive Behavior}

Finally, chi-square analyses compared stalked and not stalked group perceptions of the 47 intrusive behaviors and two were significant. Participants with experience of stalking victimization were more likely to perceive "Agreeing with your every word (even if you were wrong" to be unacceptable than participants without 
experience of stalking victimization $(83.3 \%$ vs. $63.1 \%), \chi^{2}(1)=7.61, p=.006$. In contrast, participants with experience of stalking victimization were less likely to perceive "Someone at a social event such as a party asks you if you would like to have sex with him/her" to be unacceptable than participants without experience of stalking experience $(38.9 \%$ vs. $68.1 \%), \chi^{2}(1)=14.47, p<.001$.

\section{Qualitative Analysis of Worst Experiences}

A thematic analysis was conducted on all 116 qualitative responses to Section 4 of the questionnaire. Following general familiarization, initial (topic) codes were assigned to repeating topics observed in these responses. These initial codes were then arranged into themes (analytical codes) and possible sub-themes. The themes and subthemes were reviewed to ensure their relevance and the existence of supporting evidence before being defined and named. Responses from the LGBTIQ and heterosexual groups were coded separately and resulted in three overarching themes: heterosexual experiences, shared experiences and LGBTIQ experiences. Themes and the corresponding sub-themes are presented in Figure 1.

---Figure 1 about here---

Heterosexual experiences. Heterosexual individuals believed intrusive behavior was acceptable if it presented no risk to their safety $(\mathrm{n}=11)$ : “...none cross any lines that would make me feel unsafe" (Heterosexual 1, explaining that she has experienced verbal abuse from strangers, but was not concerned as no direct threats were made), "People have been calm and non-threatening so none of them bothered me" (Heterosexual 2, describing several unrelated incidents of verbal abuse 
experienced whilst travelling on public transport) and “...he was very polite and friendly although he was a stranger" (Heterosexual 13, describing an occasion when a male was pressuring her for sex). Heterosexual individuals also described experiences as acceptable or safe if they felt in control: “...as a practicing martial artist I felt I could take care of myself" (Heterosexual 1, explaining that she was not afraid when strangers insulted her appearance) and "I was old enough to deal with it maturely" (Heterosexual 51, describing how she handled an unwanted sexual touch from an acquaintance). A second theme concerned the need of heterosexual individuals to fulfil social obligations $(\mathrm{n}=18)$ even when experiencing intrusive behavior: “...decided it would be rude/dangerous to say nothing" (Heterosexual 36, explaining why she responded to several (of hundreds) unwanted and sexually themed text messages from an acquaintance), “...while I like getting things I felt uncomfortable because I felt like I owed him something” (Heterosexual 31, describing why she was pleasant to her former partner even though she would have preferred not to have contact with him) and "He would buy me unwanted gifts all the time making me feel obliged to be nice back to him" (Heterosexual 68, explaining why she spoke with her neighbor, after he had harassed her for several years, performed sexual acts in her garden, and she had reported him to police). Although the gift giving was present in the responses of LGBTIQ individuals, the perceived social obligation to return kindness was unique to heterosexual individuals.

LGBTIQ experiences. LGBTIQ individuals experienced threats to self-harm $(n=11)$ if they did not meet the demands of their stalker: "she threatened to go and kill herself if I didn't stay the night" (LGBTIQ 4, describing her former partner who was controlling during the relationship, initiated unwanted sexual liaisons, hid in her garden to spy on her, and phoned her for hours each day), "They threatened suicide 
and to hurt me if I didn't go on a date with them" (LGBTIQ 24, talking about an acquaintance who wanted a relationship and who would regularly follow him) and “the person involved threatened to kill themselves if I didn't respond" (LGBTIQ 45, describing a similar experience to LGBTIQ 24. His stalker would send photographs of himself self-harming)". A second theme concerned intrusive behavior that related to LGBTIQ individuals' sexual orientation $(n=14)$ : “...I would still get messages from him asking if I wanted to meet up and make sure I was really gay" (LGBTIQ 27, describing a work colleague who would sexually touch her at work on a daily basis), "she did this in spite of my openness about being a gay man" (LGBTIQ 39, an animal lover, detailed how his stalker would kill small animals in a food blender and send him evidence of having done so, to prove her love for him), "the stalker came up to the driver's window and started to bang on the glass, he was shouting out my name and asking who knew that I was gay and having sex at beats" (LGBTIQ 49, describing a threatening stalker who targeted her on a daily basis for more than 18 months).

Shared experiences. Heterosexual and LGBTIQ individuals described experiences where the intrusive behavior related to unreciprocated attraction $(\mathrm{n}=$ 81): “once rejected again it was queried if we could hang out as 'friends' which was obviously a no no and that's when the verbal abuse occurred" (LGBTIQ 3, talking about her ex-partner who became aggressive if ignored),"I had told her I was not interested but she would not stop" (Heterosexual 19, describing how a school friend would write to him daily and frequently webcam him and perform sexual acts on screen) and "I told him I just wanted to be friends however he would not take no for an answer" (Heterosexual 22, who went on one date with a man, and he then sent letters and money to her and made frequent home visits). 
A second theme concerned internalization and self-blame $(n=14)$ to explain the intrusive behavior: "I never pursued the matter, thinking it was my fault" (Heterosexual 13, recounting a 14 month stalking experience) and "I suffered guilt and shame, people around me didn't know what to do" (LGBTIQ 100, recounting a serious sexual assault. A third and final theme concerned sexual assault $(\mathrm{n}=16)$, which was one of the most common of the 47 intrusive behaviors to be described in response to Section 4 of the questionnaire.

\section{Discussion}

Our first hypothesis, that LGBTIQ individuals would perceive intrusive behavior similarly to heterosexual individuals, was supported. It is unclear whether this finding would remain, however, if a vignette were presented rather than a list of behaviors. Studies using vignette methodologies to describe stalking situations have tended to produce more marked between-group findings than those employing the current methodology (e.g., Dennison \& Thomson, 2002; Phillips, Quirk, Rosenfeld, \& O'Connor, 2004). This issue is explored further below. Our findings support the second hypothesis, that LGBTIQ individuals would report having experienced more intrusive behaviors than heterosexual individuals, and are consistent with previous works that identified higher than general population rates of relational violence, postrelational violence, and harassment for LGBTIQ individuals (see e.g., Katz-Wise \& Hyde's 2012 meta-analysis). Furthermore, the behaviors experienced at higher rates by LGBTIQ individuals tended towards the more serious end of the scale (e.g., verbal abuse, physical harm, forced sexual contact and threats). As such, whilst perceptions of the acceptability of the 47 intrusive behaviors varied little according to sexual 
orientation, nearly half of these behaviors were experienced at higher rates by LGBTIQ individuals.

Our findings also support the third hypothesis, that LGBTIQ individuals would report higher rates of stalking victimization than heterosexual individuals. The thematic analysis revealed substantive differences in the experiences reported by LGBTIQ and heterosexual groups. Although unable to relate their conclusions to sexual orientation, Strand and McEwan (2011) found opposite-sex stalker motivations to be mainly rooted in prior-intimate relationships, with same-sex stalkers being more motivated by a grievance against the victim, and consequent anger and selfrighteousness. One of the themes pertaining to LGBTIQ individuals concerned victimization associated with a failure to accept their sexual orientation. Future work should examine whether this finding reflects Strand and McEwan's grievance motivation. The characteristics of LGBTIQ and heterosexual stalkers and their respective victims need to be recorded in order to better understand past and present findings. The role of gender also needs to be assessed as sex of the perpetrator and victim are well-known predictors of stalking (with the modal stalker being a man and the modal victim being a woman, e.g., Meloy, 1999). However, some works have concluded that factors such as stalker motivation are more important when examining predictors of the processes and consequences of stalking (e.g., Pathé, Mullen, \& Purcell, 2000; Sheridan, North, \& Scott, 2014; Strand \& McEwan, 2012).

Our fourth hypothesis, that women and men would judge the intrusive behaviors to be unacceptable at similar rates, was supported. This finding is in line with previous works that have employed this methodology, but does not tally with findings from studies that present vignettes describing a typical stalking case. A possible explanation concerns the defensive attribution bias (see e.g., Elkins et al., 
2002). Compared with vignettes, lists of intrusive behaviors are less context dependent and do not easily allow respondents to identify with the gender stereotyped role of victim or perpetrator. Further, it has been argued that the stalking vignettes used by prior works tend to depict modal stalking behaviors as engaged in by men towards women, (Langhinrichsen-Rohling, 2012). As such, it is recommended that findings from studies employing vignettes versus list methodologies should be differentiated rather than being considered in concert, and that vignette studies seek to include behaviors more typically engaged in by female stalkers. Hypothesis five, which predicted that people with experience of stalking victimization would judge more intrusive behaviors to be unacceptable than people without experience of stalking victimization, was not supported. As with our first and fourth hypotheses, this finding could be an artefact of the measure we used. That is, it may be that the list of 47 intrusive behaviors does not reflect gender scripts to the same degree as vignettes that describe stalking situations, because the behaviors are less extreme and less stereotypically male, and also because participants are identifying less closely with victim or perpetrator roles. To further ascertain the impact of methodology, future studies that employ the 47-item scale used in the present research could collect responses via a Likert scale to produce more discriminate findings. .

The results have both practical and research related implications. It is important to study perceptions of stalking and intrusive behavior because stalking is notoriously difficult to define. Identification of which intrusive behaviors people consider unacceptable provides insight into what types of intrusions (that may or may not constitute stalking) they would likely bring to the attention of police or other authorities. Also, work on perceptions of unwanted interpersonal acts frequently identifies myths, which in turn have been demonstrated as leading to minimization of 
criminal acts, victim blaming, and favoring offenders (e.g. Suarez \& Gadalla, 2010). In the present research, the findings suggest that members of the LGBTIQ community are not overly sensitive when perceiving themselves as victims ('playing the bias card'), given the similarity between LGBTIQ and heterosexual group ratings of the acceptability of our 47 intrusive behaviors. Internet searches suggest that this 'playing the bias card' misperception may be widely held. There is a surprising lack of research on this issue, and it needs to be addressed by future work. Another implication concerns interactions with victims. Given the nebulous and chronic nature of stalking, investigators and victim supporters need to be equipped with specific knowledge concerning the course and nature of stalking. It is often not easy to elicit comprehensive responses from victims, who may describe their victimization in piecemeal terms (see Copson \& Marshall, 2002). Also, stalking myths are commonly held (e.g. McKeon et al., 2015) which may further inhibit the recounting and acknowledgment of a complete story. An understanding that the motivations for and manifestations of stalking can differ for members of diverse groups within the community can only aid in developing fruitful dialogues between victims and their allies.

It is important to acknowledge that the present samples were self-selected. There is always a risk that any work that advertises itself as stalking, or harassment, focused will over recruit individuals with experience of stalking victimization, and it is not known whether this self-selection applied equally to the LGBTIQ and heterosexual groups. However, the two groups were matched on three demographic variables in an attempt to overcome this issue. Furthermore, the present research used a well-established measure and took a mixed-methods approach to better understand the stalking experiences of both LGBTIQ and heterosexual individuals. The 
qualitative analysis revealed that although participants described some overlapping experiences, other experiences were only present within either the LGBTIQ or the heterosexual group. Mixed-methods research is rarely applied to stalking and may provide a better understanding of this complex phenomenon than quantitative methods alone.

In conclusion, LGBTIQ individuals reported higher levels of experiencing a range of individual intrusive behaviors and stalking than heterosexual individuals. There is reason to believe that the nature of, and motivations for, the stalking of LGBTI and heterosexuals differ. The qualitative findings indicate that some LGBTIQ people are harassed because of their sexual orientation. Further research is necessary therefore on larger, culturally diverse samples in order to further explore the experiences of LGBTIQ individuals. While the present research has investigated LGBTIQ individuals as victims, it did not determine who the perpetrators were or the prior relationship status and (non-binary) sex of the perpetrator and victim. Continued work is necessary in this area as different interventions and advice may be appropriate for LGBTIQ individuals who experience inter-personal intrusions and stalking. 


\section{References}

Australian Bureau of Statistics. (2010). Customised report. Based on data from the 2005 Personal Safety Survey. Canberra, Australia: Australian Bureau of Statistics.

Baum, K., Catalano, S., Rand, M., \& Rose, K. (2009). Stalking Victimization in the United States. Washington, DC: US Department of Justice, Office of Justice Programs.

Bjorklund, K., Hakkanen-Nyholm, H., Sheridan, L., \& Roberts, K. (2010). The prevalence of stalking among Finnish University students. Journal of Interpersonal Violence, 25, 684-698. doi: 10.1177/0886260509334405

Carvalho, A. F., Lewis, R. J., Derlega, V. J., Winstead, B. A., \& Viggiano, C. (2011). Internalized sexual minority stressors and same-sex intimate partner violence. Journal of Family Violence, 26, 501-509. doi: 10.1007/s10896-011-9384-2

Cass, A. I. (2011). Defining stalking: The influence of legal factors, extralegal factors, and particular actions on judgments of college students. Western Criminology Review, 12, 1-14.

Cass, A. I., \& Rosay, A. B. (2012). College student perceptions of criminal justice system responses to stalking. Sex Roles, 66, 392-404. doi: 10.1007/s11199-011$9934-3$

Chapman, D. E., \& Spitzberg, B. H., (2003). Are you following me? A study of unwanted relationship pursuit and stalking in Japan: What behaviours are prevalent? Bulletin of Hijiyama University, 10, 89-117.

Chiri, L. R., Sica, C., Roberts, K., \& Sheridan, L. (2009). Il fenomeno dello stalking: Inquadramento teorico e dati preliminari su un campione Italiano (The phenomenon of stalking: Theoretical aspects and preliminary data on an Italian 
sample). Rassegna di Psicologia, 26, 119-140. doi: 10.7379/70565

Comfort, J., \& McCausland, K. (2013). Health priorities and perceived health determinants among Western Australians attending the 2011 LGBTI Perth Pride Fairday Festival. Health Promotion Journal of Australia, 24, 20-25. doi: 10.1071/HE12906

Copson, G., \& Marshall, N. (2002). Police care and support for victims of stalking. In J. Boon \& L. Sheridan (Eds.). Stalking and psychosexual obsession: Psychological perspectives for prevention, policing and treatment (pp. 49-62). Chichester: Wiley.

Cupach, W. R. \& Spitzberg, B. H. (2004). The dark side of relationship pursuit: From attraction to obsession and stalking. Mahwah, NJ: Lawrence Erlbaum Associates.

Dank, M., Lachman, P., Zweig, J. M., \& Yahner, J. (2014). Dating violence experiences of lesbian, gay, bisexual, and transgender youth. Journal of Youth and Adolescence, 43, 846-857. doi: 10.1007/s10964-013-9975-8

Dennison, S. M., \& Thomson, D. M. (2002). Identifying stalking: The relevance of intent in commonsense reasoning. Law and Human Behavior, 26, 543-561. doi: 10.1023/A:1020256022568

Derlega, V. J., Winstead, B. A., Pearson, M. R., Janda, L. J., Lewis, R. J., Dutton, L. B., ... Greene, K. (2011). Unwanted pursuit in same-sex relationships: Effects of attachment styles, investment model variables, and sexual minority stressors. Partner Abuse, 2, 300-322. doi: 10.1891/1946-6560.2.3.300

Elkins, T. J., Philips, J. S., \& Konopaske, R. (2002). Gender-related biases in evaluations of sex discrimination allegations: Is perceived threat the key? Journal of Applied Psychology, 87, 280-292. doi: 10.1037//0021-9010.87.2.280 
Englebrecht, C. M., \& Reyns, B. W. (2011). Gender differences in acknowledgment of stalking victimization: Results from the NCVS stalking supplement. Violence and Victims, 26, 560-579. doi: 10.1891/0886-6708.26.5.560

Fairchild, K. (2010). Context effects on women's perceptions of stranger harassment. Sexuality and Culture, 14, 191-216. doi: 10.1007/s12119-010-9070-1

Finnegan, H. A., \& Timmons Fitz, P. A. (2012). Differential effects of gender on perceptions of stalking and harassment behaviour. Violence and Victims, 27, 895-910. doi: 10.1891/0886-6708.27.6.895

Fisher, B. S., Cullen, F. T., \& Turner, M. G. (2002). Being pursued: Stalking victimization in a national study of college women. Criminology \& Public Policy, 1, 257-308. doi: 10.1111/j.1745-9133.2002.tb00091.x

Garcia, M. M. (2010). Voices from the fields: Stalking National Institute of Justice Journal, 66, 14-15. doi: 10.1177/0886260511416473

Hills, A. M., \& Taplin, J. L. (1998). Anticipated responses to stalking: Effect of threat and target-stalker relationship. Psychiatry, Psychology and Law, 5, 139-146. doi: $10.1080 / 13218719809524927$

Jagessar, J. D. H., \& Sheridan, L. P. (2004). Stalking perceptions and experiences across two cultures. Criminal Justice and Behavior, 31, 97-119. doi: $10.1177 / 0092854803259244$

Jordan, C. E., Wilcox, P., \& Pritchard, A. J. (2007). Stalking acknowledgement and reporting among college women experiencing intrusive behaviors: Implications for the emergence of a "classic stalking case". Journal of Criminal Justice, 35, 556-569. doi: 10.1016/j.jcrimjus.2007.07.008 
Katz-Wise, S. L., \& Hyde, J. S. (2012). Victimization experiences of lesbian, gay, and bisexual individuals: A meta-analysis. Journal of Sex, 49, 142-167. doi: $10.1080 / 00224499.2011 .637247$

Kinkade, P., Burns, R., \& Fuentes, A. L. (2005). Criminalizing attractions: Perceptions of stalking and the stalker. Crime and Delinquency, 51, 3-25. doi: $10.1177 / 0011128703262462$

Lambert, E. G., Smith, B., Geistman, J., Cluse-Tolar, T., \& Jiang, S. (2013). Do men and women differ in their perceptions of stalking: An exploratory study among college students. Violence and Victims, 28, 195-209. doi: 10.1891/08866708.09-201

Langhinrichsen-Rohling, J. (2012). Gender and stalking: Current intersections and future directions. Sex Roles, 66, 418-426. doi: 10.1007/s11199-011-0093-3

McEwan, T. E., Mullen, P. E., \& Purcell, R. (2007). Identifying risk factors in stalking: A review of current research. International Journal of Law and Psychiatry, 30, 1-9. doi: 10.1016/j.ijlp.2006.03.005

McKeon, B., McEwan, T. E., \& Luebbers, S. (2015). 'It's not really stalking if you know the person': Measuring community attitudes that normalize, justify and minimise stalking. Psychiatry, Psychology and Law, 22, 291-306. doi: $10.1080 / 13218719.2014 .945637$

Meloy, J. R. (1999). Stalking: An old behavior, a new crime. Psychiatric Clinics of North America, 22, 85-99. doi: 10.1016/S0193-953X(05)70061-7

Pathé, M., Mullen, P. E., \& Purcell, R. (2000). Same-gender stalkers. Journal of the American Academy of Psychiatry and the Law, 28, 191-197. 
Pereira, F., Matos, M., Sheridan, L., \& Scott, A. J. (2015). Perceptions and personal experiences of unwanted attention among Portuguese male students. Psychology, Crime \& Law, 21, 398-411. doi: 10.1080/1068316X.2014.989167

Philips, F., \& Morrissey, G. (2004). Cyberstalking and cyberpredators: A threat to safe sexuality on the internet. Convergence, 10, 66-79. doi: $10.1177 / 135485650401000105$

Phillips, L., Quirk, R., Rosenfeld, B., \& O’Connor, M. (2004). Is it stalking? Perceptions of stalking among college undergraduates. Criminal Justice and Behavior, 31, 73-96. doi: 10.1177/0093854803259251

Ravensburg, V., \& Miller, C. (2003). Stalking among young adults. A review of preliminary research. Aggression and Violent Behavior, 8, 455-469. doi: $10.1016 / \mathrm{S} 1359-1789(02) 00075-7$

Reyns, B. W., Henson, B., Fisher, B. S., Fox, K. A., \& Nobles, M. R. (2015). A gendered lifestyle-routine activity approach to explaining stalking victimization in Canada. Journal of Interpersonal Violence, Advance online publication. doi: $10.1177 / 0886260515569066$

Scott, A. J., Rajakaruna, N., Sheridan, L., \& Gavin, J. (2015). International perceptions of relational stalking: The influence of prior relationship, perpetrator sex, target sex and participant sex. Journal of Interpersonal Violence, 30, 3308-3323. doi: 10.1177/0886260514555012

Sheridan, L., Davies, G. M., \& Boon, J. C. (2001). Stalking perceptions and prevalence. Journal of Interpersonal Violence, 16, 151-167. doi: $10.1177 / 088626001016002004$

Sheridan, L., Gillett, R., \& Davies, G. (2000). 'Stalking'- Seeking the victim’s perspective. Psychology, Crime \& Law, 6, 267-280. doi: 


\section{$10.1080 / 10683160008409807$}

Sheridan, L., Gillett, R., \& Davies, G. (2002). Perceptions and prevalence of stalking in a male sample. Psychology, Crime \& Law, 8, 289-310. doi: $10.1080 / 10683160208401821$

Sheridan, L., \& Lyndon, A. E. (2012). The influence of prior relationship, gender, and fear on the consequences of stalking victimization. Sex Roles, 66, 340-350. doi: 10.1007/s11199-010-9889-9

Sheridan, L. P., North, A. C., \& Scott, A. J. (2014). Experiences of stalking in samesex and opposite-sex contexts. Violence and Victims, 29, 1014-1028. doi: 10.1891/0886-6708.VV-D-13-00072

Sheridan, L., Scott, A. J., \& North, A. C. (2014). Stalking and age. Journal of Threat Assessment and Management, 1, 262-273. doi: 10.1037/tam0000023

Simpson, B., \& Eriksson, K. (2011). A lay-statistician explanation of minority discrimination: A research note. Social Science Research, 41, 637-645. doi: 10.1016/j.ssresearch.2011.12.009

Sinclair, H. C. (2012). Stalking myth-attributions: Examining the role of individual and contextual variables on attributions in unwanted pursuit scenarios. Sex Roles, 66, 378-391. doi: 10.1007/s11199-010-9853-8

Sinclair, H. C., \& Frieze, I. H. (2002). Initial courtship behaviour and stalking: How should we draw the line? In J. A. Davis, I. H. Frieze, \& R. D. Maiuro (Eds.), Stalking: Perspectives on victims and perpetrators (pp. 186-211). New York: Springer Publishing Company.

Spitzberg, B. H., \& Cupach, W. R. (2007). The state of the art of stalking: Taking stock of the emerging literature. Aggression and Violent Behavior, 12, 64-86. doi: 10.1016/j.avb.2006.05.001 
Strand, S., \& McEwan, T. E. (2011). Same-gender stalking in Sweden and Australia. Behavioral Sciences \& the Law, 29, 202-219. doi; 10.1002/bsl.981

Strand, S., \& McEwan, T. E. (2012). Violence among female stalkers. Psychological Medicine, 42, 545-555. doi: 10.1017/S0033291711001498

Suarez, E. \& and Gadalla, T.B. (2010). Stop blaming the victim: A meta-analysis on rape myths. Journal of Interpersonal Violence, 25, 2010-2035. doi: $10.1177 / 0886260509354503$

Yanowitz, K. L. (2006). Influence of gender and experience on college students' stalking schemas. Violence and Victims, 21, 91-100. doi: 10.1891/08866708.21 .1 .91 
Table 1

Participant demographics

LGBTIQ Heterosexual

Sex

Male

$37.4 \%$

$37.4 \%$

Female

$57.0 \%$

$62.6 \%$

Other

$5.6 \%$

0

Age

$\begin{array}{lrr}18-21 \text { years } & 30.7 \% & 30.7 \% \\ 21-30 \text { years } & 35.5 \% & 35.5 \% \\ 31-40 \text { years } & 15.0 \% & 15.0 \% \\ 40-50 \text { years } & 8.4 \% & 8.4 \% \\ 50+\text { years } & 10.3 \% & 10.3 \%\end{array}$

Income

$\begin{array}{lll}\$ 0-\$ 30,000 * & 58.9 \% & 58.9 \% \\ \$ 30,000-\$ 70,000 & 25.2 \% & 25.2 \% \\ \$ 70,000+ & 15.9 \% & 15.9 \%\end{array}$

Note. Age groupings and income brackets (rather than precise figures) were requested in order to assure anonymity and remain as unobtrusive as possible.

*Australian dollars. National mean earnings in November $2014=\$ 76.562$, with $70 \%$ of adult Australians earning or receiving less than this figure (ABS, weekly earnings update 6302.0, November 2014) 
Table 2

Significant chi-square analyses comparing LGBTIQ $(n=107)$ and heterosexual $(n=$ 107) group perceptions of the 47 intrusive behaviors as unacceptable

\begin{tabular}{|c|c|c|c|c|c|}
\hline \multirow[b]{2}{*}{ Intrusive behavior } & \multicolumn{2}{|c|}{ LGBTIQ } & \multicolumn{2}{|c|}{ Heterosexual } & \multirow[b]{2}{*}{$\chi^{2}(1)$} \\
\hline & $n$ & $\%$ & $n$ & $\%$ & \\
\hline $\begin{array}{l}\text { Agreeing with your every word (even if you } \\
\text { were wrong). }\end{array}$ & 80 & 74.8 & 66 & 61.7 & $4.23^{*}$ \\
\hline Doing unrequested favors for you. & 64 & 59.8 & 47 & 43.9 & $5.41^{*}$ \\
\hline Asking friends, family, school or work & 53 & 49.5 & 34 & 31.8 & $6.99^{* *}$ \\
\hline \multicolumn{6}{|l|}{ colleagues about you. } \\
\hline $\begin{array}{l}\text { A stranger offering to buy you a drink in a } \\
\text { café, restaurant or bar. }\end{array}$ & 21 & 19.6 & 9 & 8.4 & $5.58^{*}$ \\
\hline Someone at a social event such as a party asks & 57 & 53.3 & 73 & 68.2 & $5.02^{*}$ \\
\hline \multicolumn{6}{|l|}{ you if you would like to have sex with } \\
\hline him/her. & & & & & \\
\hline 'Wolf-whistling' in the street. & 90 & 84.1 & 76 & 71.0 & $5.26^{*}$ \\
\hline
\end{tabular}

Notes. ${ }^{*} p<.05 .{ }^{* *} p<.01$. The higher $\%$ scores are presented in bold. 
Table 3

Significant chi-square analyses comparing LGBTIQ $(n=107)$ and heterosexual $(n=$ 107) group experiences of the 47 intrusive behaviors

\begin{tabular}{|c|c|c|c|c|c|}
\hline \multirow[b]{2}{*}{ Intrusive behavior } & \multicolumn{2}{|c|}{ LGBTIQ } & \multicolumn{2}{|c|}{ Heterosexual } & \multirow[b]{2}{*}{$\chi^{2}(1)$} \\
\hline & $n$ & $\%$ & $n$ & $\%$ & \\
\hline $\begin{array}{l}\text { Sending you unwanted letters, notes, e-mails } \\
\text { or other written communications. (94.5\%). }\end{array}$ & 68 & 63.6 & 48 & 44.9 & $7.53^{* *}$ \\
\hline $\begin{array}{l}\text { Threatening to kill or hurt her/himself if you } \\
\text { refused to go out on a date with him/her. } \\
(99.5 \%) \text {. }\end{array}$ & 29 & 27.1 & 12 & 11.2 & $8.72^{* *}$ \\
\hline Following you. (96.7\%). & 48 & 44.9 & 24 & 22.4 & $12.06^{* * *}$ \\
\hline Visiting places because s/he knows that you & 63 & 58.9 & 43 & 40.2 & $7.48^{* *}$ \\
\hline may be there. $(64 \%)$. & & & & & \\
\hline Asking you for a date repeatedly. (81.3\%). & 55 & 51.4 & 39 & 36.4 & $4.86^{*}$ \\
\hline Verbally abusing you. (99.5\%). & 65 & 60.7 & 48 & 44.9 & $5.42^{*}$ \\
\hline Someone at a social event such as a party asks & 66 & 61.7 & 46 & 43.0 & $7.49^{* *}$ \\
\hline you if you would like to have sex with & & & & & \\
\hline him/her. $(60.7 \%)$. & & & & & \\
\hline Hurting you emotionally (verbal abuse, & 69 & 64.5 & 53 & 49.5 & $4.88^{*}$ \\
\hline ruining your reputation). (100\%). & & & & & \\
\hline Refusing to accept that a prior relationship is & 53 & 49.5 & 34 & 31.8 & $6.99^{* *}$ \\
\hline over. $(96.3 \%)$. & & & & & \\
\hline $\begin{array}{l}\text { Standing and waiting outside your home. } \\
(96.7 \%) \text {. }\end{array}$ & 38 & 35.5 & 23 & 21.5 & $5.16^{*}$ \\
\hline $\begin{array}{l}\text { Seeing him/her at the same time each day. } \\
(45.3 \%) \text {. }\end{array}$ & 48 & 44.9 & 34 & 31.8 & $3.86^{*}$ \\
\hline Harming you physically. (99.5\%). & 34 & 31.8 & 19 & 17.8 & $5.64^{*}$ \\
\hline
\end{tabular}




\begin{tabular}{lccccc}
\hline Forced sexual contact. (99.5\%). & 48 & $\mathbf{4 4 . 9}$ & 26 & 24.3 & $10.00^{* *}$ \\
Coming round to visit you, uninvited, on a & 41 & $\mathbf{3 8 . 3}$ & 26 & 24.3 & $4.89^{*}$ \\
regular basis. (91.1\%). & & & & & \\
Confining you against your will. (100\%). & 26 & $\mathbf{2 4 . 3}$ & 11 & 10.3 & $7.35^{* *}$ \\
Spying on you. (98.6\%). & 33 & $\mathbf{3 0 . 8}$ & 19 & 17.8 & $4.98^{*}$ \\
Threatening to physically hurt you. (99.5\%). & 36 & $\mathbf{3 3 . 6}$ & 20 & 18.7 & $6.19^{*}$ \\
Physically hurting someone you care about. & 11 & $\mathbf{1 0 . 3}$ & 2 & 1.9 & $6.63^{* *}$ \\
(100\%). & & & & & \\
Making arrangements without asking you first & 58 & $\mathbf{5 4 . 2}$ & 40 & 37.4 & $6.10^{*}$ \\
(e.g., booking a table at a restaurant). (66.8\%). & & & & & \\
'Outstaying his/her welcome' in your home. & 61 & $\mathbf{5 7 . 0}$ & 45 & 42.1 & $4.79^{*}$ \\
(92.5\%). & & & & &
\end{tabular}

\footnotetext{
Notes. ${ }^{*} p<.05 .{ }^{* *} p \leq .01 .{ }^{* * *} p \leq .001$. The higher $\%$ scores are presented in bold. Percentages in parentheses following each behavior indicate the proportion of the total sample who judged the behavior as "unacceptable".
} 
Figure 1.

Thematic map: Personal experiences of stalking victimization.

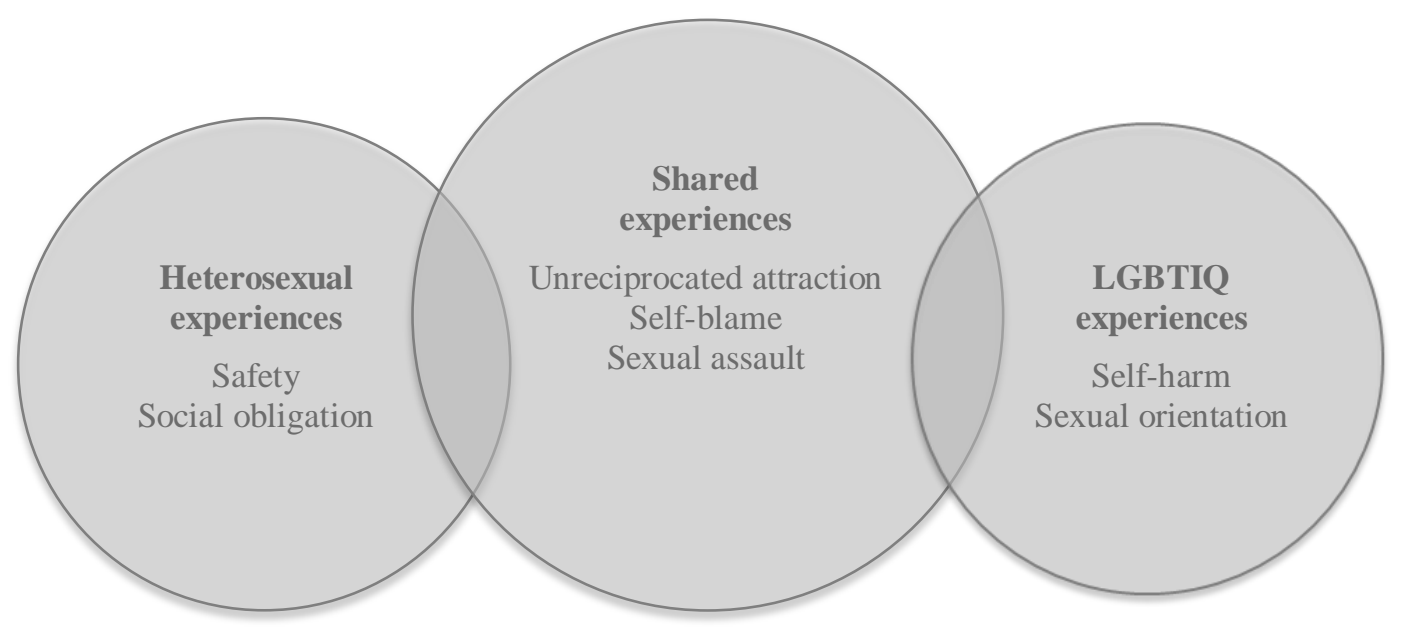

